DOI: https://doi.org/10.47405/mjssh.v6i3.719

\begin{tabular}{|c|c|}
\hline 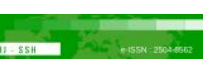 & Malaysian Journal of Social Sciences and Humanities (MJSSH) \\
\hline Malaysian Journal of & Volume 6, Issue 3, March 2021 \\
\hline (MJ-SSH) & e-ISSN : 2504-8562 \\
\hline & $\begin{array}{l}\text { Journal home page: } \\
\text { www.msocialsciences.com }\end{array}$ \\
\hline
\end{tabular}

\title{
Adolescent to Adolescent Transformation Program- Nurturing, Enhancing and Promoting Adolescents' Healthy Habit (ATAP- NEPAH): Curbing Social Problems Among Adolescents in Kelantan Through Peer-To-Peer Health Education
}

\author{
Azriani Ab Rahman1, Mohd Ismail Ibrahim 1, Faridah MohdZin², Razlina Abdul Rahman², \\ Nur Suhaila Idris ${ }^{2}$, Rosnani Zakaria ${ }^{2 .}$, Imran Ahmad ${ }^{2}$, Asrenee Ab Razak ${ }^{3}$, Maruzairi \\ Husain ${ }^{3}$, Mohd Azhar Mohd Yasin ${ }^{3}$, Norzila Zakaria ${ }^{3}$, Hans Van Rostenberghe ${ }^{4}$, Azizah \\ Othman ${ }^{4}$, Fahisham Taib4, Surini Yusof ${ }^{4}$, Nor Rosidah Ibrahim ${ }^{4}$, Norsarwany Mohamad", \\ Noorizan H A Majid ${ }^{4}$, Rahimah Zakaria ${ }^{5}$, Muhamad Saiful Bahri Yusoff ${ }^{6}$, Mohd Najib Mat Pa', \\ Mohd Zarawi Mat Nor', Shaik Farid Abdull Wahab ${ }^{7}$, Mohd Hashairi Fauzi ${ }^{7}$, Dasmawati \\ Mohamad $^{8}$, Nazeli Hamzah ${ }^{9}$ \\ ${ }^{1}$ Department of Community Medicine, School of Medical Sciences, Universiti Sains Malaysia (USM) \\ 2Department of Family Medicine, School of Medical Sciences, Universiti Sains Malaysia (USM) \\ ${ }^{3}$ Department of Psychiatry, School of Medical Sciences, Universiti Sains Malaysia (USM) \\ ${ }^{4}$ Department of Pediatrics, School of Medical Sciences, Universiti Sains Malaysia (USM) \\ ${ }^{5}$ Department of Physiology, School of Medical Sciences, Universiti Sains Malaysia (USM) \\ ${ }^{6}$ Department of Medical Education, School of Medical Sciences, Universiti Sains Malaysia (USM) \\ ${ }^{7}$ Department of Emergency Medicine, School of Medical Sciences, Universiti Sains Malaysia (USM) \\ ${ }^{8}$ School of Dental Sciences, Universiti Sains Malaysia (USM) \\ ${ }^{9}$ Malaysian Association for Adolescent Health (MAAH) \\ Correspondence: Azriani Ab Rahman (azriani@usm.my)
}

\begin{abstract}
The objectives of ATAP-NEPAH are to enhance and nurture healthy habits among adolescents as well as to empower adolescents in inculcating these healthy habits among them. Health education through peer-to-peer approach is used to instill the knowledge on important areas such as sexual and reproductive health, smoking, substance abuse, illegal street racing ( rempit) and mental health. Specific modules were developed by experts (lecturers) in multidisciplinary fields in collaboration with Malaysian Association for Adolescent Health (MAAH), National Population and Family Development Board (NPFDB), Reproductive Health Association of Kelantan (REHAK) and Rhaudatus Sakinah Kelantan. The trained Medical Students Facilitator Team (MSFT) of USM became trainers to secondary one school students. The selected school students were trained by the medical students to become peer educators to their juniors and peers. There was improvement in the readiness level of peer educators, knowledge and attitude towards healthy habits and risky behaviors of other school students after the intervention.
\end{abstract}

Keywords: Peer to peer, health education, risky behaviors, adolescents

\section{Introduction}

Adolescents are known to have specific morbidities resulting from their behaviors. Among the main problems of Malaysian youths are sexual and reproductive issues, smoking, substance abuse, illegal 
street racing and mental health problems (Health, 2017). Lack of knowledge (Rahman et al., 2011) and skills in negotiating risky behaviors as well as peer influence are important risk factors contributing to the problems. Young people learn from and influence each other, either in risky or in safe behaviors (Maticka-Tyndale \& Barnett, 2010; Toolkit, 2005).Traditional health education often does not meet the need of adolescents (Yeager, Dahl, \& Dweck, 2018). Peers have a major and perhaps greater influence on a young person's health behavior than health care providers. Peer to peer education approach which empowers the positive influence of peers was found to be effective in influencing adolescents' knowledge, attitude and behavior (Abdi \& Simbar, 2013). Thus, ATAP-NEPAH is introduced as an innovative health education which is led by peers. It emphasizes on skill-building, problem-solving, communication-based and engagement of young people.

\section{Description of the program}

The aims of the ATAP-NEPAH program were to nurture healthy habits and avoid risky behaviors among adolescents in Kelantan as well as to empower adolescents in inculcating these healthy habits among them. Health education through peer - to - peer approach was used to instil the knowledge on important areas such as sexual and reproductive health (SRH), smoking, substance abuse, illegal street racing (rempit) and mental health using specific modules.

The modules were developed by medical and health professionals who are also academicians working in multidisciplinary departments of Universiti Sains Malaysia (USM) Health Campus. A meeting with selected school teachers and students was held prior to the module development to identify the need such as common problems faced by the students, the information and services required. In general, the objectives of the modules were to empower adolescents with appropriate knowledge to enable them to practice healthy behaviors, to empower them with assertive skills to avoid risky and unhealthy behaviors, to assist adolescents in building up important skills in life such as communication, problem solving and decision making skills, to nurture important positive values and attitude such as positive self esteem and self-confidence and to empower adolescents to be responsible for their behaviors. The information was delivered through active participation of adolescents involving different types of interactive activities such as role play, drawing, debate, quizzes, video show and small group discussions. For content validity, the modules were validated by the experts from non-governmental agencies which have vast experience in conducting adolescent health education program in Malaysia such as Malaysian Association for Adolescent Health (MAAH), Reproductive Health Association of Kelantan (REHAK), National Population and Family Development Board (NPFDB) and Rhaudatus Sakinah. The modules were then tested for its face validity among a group of medical students. The content and the method of health education was then refined according to the feedback given by the medical students.

Medical students were then trained by the lecturers (content experts) to convey the message to school students using the modules. The selected school students were then trained to become peer educators to their juniors and peers. For peer educators, the school students were selected by the medical students with the help of the school teachers. The peer educators consist of good and problematic students with regard to their behaviours. This program was targeted to thirteen- year- old (secondary one) students which represent young group of adolescents.

\section{Method of evaluation}

A cross sectional study was conducted to evaluate the effect of the program. A total of 100 thirteen -year -old school students who received health education were assessed to determine their level of knowledge and attitude towards healthy habits and risky behaviors before and after the program. While a total of thirty selected school students who were trained as peer educators were assessed for any improvement in their level of readiness to become peer educators. 
A validated questionnaire to assess knowledge and attitude of adolescents towards healthy habits and risky behaviors was distributed to the school students before and immediately after the health education program. It consists of knowledge and attitude towards four main aspects of health education module (sexual and reproductive health, smoking and substance abuse, illegal street racing and mental health). The students were assessed through a self-administered, anonymous questionnaire but were guided in answering the questions. Categorical responses (True/False/Don't know) were assigned for the knowledge components. A correct response was given a score of 2 , an incorrect response was given a score of 0 , and an answer of don't know was given a score of 1 . The questions for the attitude components were put forward in both acceptable and unacceptable statements. An ordinal response for an acceptable item ("Strongly Agree," "Agree," "Not Sure," "Not Agree," and "Strongly Not Agree") scores "4," "3," " 2 ," " 1 ," and " 0 ," respectively, and vice versa. The questionnaire has good internal consistency reliability (Cronbach's Alpha of 0.79).

My peer educator readiness scale (My Peers) was used to assess the readiness of the school students to become peer educators. It assesses readiness of the peer educators to become sibling (to share experience, support and help peers), to be ears and eyes (helping in early detection and notification of peers' problems to the responsible persons), to become counselors (trying to solve peers' problem according to their ability, to recognize peers' potential, and to motivate and supervise the peers), to become role-model (to show examples of good attitude to the peers) and to become trainers (to act as facilitators in the peer development activities). The level of readiness ranks from zero percent $(0 \%)$ to hundred percent $(100 \%)$. The scale has good internal consistency reliability (Cronbach's Alpha of 0.787 ).

\section{Result}

There was statistically significant improvement in the knowledge and attitude of students towards SRH, the danger of smoking and attitude towards road safety after the program (table 1).

Table 1: Knowledge and attitude of form one students before and after intervention $(n=100)$

\begin{tabular}{llll}
\hline & $\begin{array}{l}\text { PRE } \\
\text { Mean (SD) }\end{array}$ & $\begin{array}{l}\text { POST } \\
\text { Mean (SD) }\end{array}$ & p value* \\
\hline KNOWLEDGE & & & \\
SRH & $5.7(1.48)$ & $8.2(2.10)$ & $<\mathbf{0 . 0 0 1}$ \\
Smoking & $10.4(1.78)$ & $11.3(2.09)$ & $<\mathbf{0 . 0 0 1}$ \\
ATTITUDE & & & \\
SRH & $9.8(3.00)$ & $10.4(3.30)$ & $\mathbf{0 . 0 3 0}$ \\
Smoking & $2.6(1.27)$ & $4.3(1.44)$ & $<\mathbf{0 . 0 0 1}$ \\
Road safety & $3.2(1.54)$ & $4.5(1.67)$ & $<\mathbf{0 . 0 0 1}$ \\
\hline *paired t test & & &
\end{tabular}

For peer educators, there were significant improvement in the median score of readiness to become eye and ears ( $\mathrm{p}$ value $=0.003)$, to become counselors $(\mathrm{p}$ value $=0.002)$ and to become trainers $(\mathrm{p}$ value $=0.012)$ (table 2). 
Table 2: Score of readiness among peer educators before and after peer educators training $(n=30)$

\begin{tabular}{|c|c|c|c|}
\hline & Median (IQR) & $\begin{array}{l}\text { Median } \\
\text { (IQR) }\end{array}$ & $\begin{array}{l}\text { p } \\
\text { value* }\end{array}$ \\
\hline $\begin{array}{l}\text { Sibling: } \\
\text { Sharing experience, support and help peers }\end{array}$ & $100.0(40)$ & $100(20)$ & .236 \\
\hline $\begin{array}{l}\text { Eyes and Ears: } \\
\text { Helping in early detection and notification of } \\
\text { peers' problems to the responsible persons }\end{array}$ & $77.5(20)$ & $80(25)$ & .003 \\
\hline $\begin{array}{l}\text { Counselor: } \\
\text { Trying to solve peers' problem according to } \\
\text { ability, to recognize peers' potential, and to } \\
\text { motivate and supervise the peers }\end{array}$ & $60.0(40)$ & $80(40)$ & .002 \\
\hline $\begin{array}{l}\text { Role-model: } \\
\text { Showing examples of good attitude to the peers }\end{array}$ & $80.0(28)$ & $80(43)$ & .618 \\
\hline $\begin{array}{l}\text { Trainer: } \\
\text { Acting as facilitator in the peer development } \\
\text { activities }\end{array}$ & $60.0(20)$ & $80(40)$ & .012 \\
\hline
\end{tabular}

* Wilcoxon signed ranks test

\section{Discussion}

In line with other studies (Ali, Osman, Ibrahim, \& Ahmed, 2015; Layzer, Rosapep, \& Barr, 2017; Moran, Walker, Alexander, Jordan, \& Wagner, 2017), our study proved that peer - to - peer approach of health education improved the knowledge and attitude of adolescents towards healthy habits and risky behaviors. Adolescents are more comfortable to interact, share and discuss issues or problems among them as compared to adults. Using peers to influence and empower adolescents in inculcating the healthy habits among them provides a long-lasting impact. Both good and problematic students were selected as peer educators so that students with different types of behavior and personality might be captured and influenced. It is assumed that they have better communication and understanding towards each other which may ease the process of behavior change. Over the past half-century, scholars have made remarkable progress in demonstrating the nature and impact of peer influence on the lives of adolescents (Brown, Bakken, Ameringer, \& Mahon, 2008).

As young people, medical students play as good role models and peers to the school students, thus facilitating the knowledge transfer to the school students (Bretelle et al., 2014). As peers, it was easier for the school students to communicate with medical students (Jobanputra, Clack, Cheeseman, Glasier, $\&$ Riley, 1999). Engagement of medical students as facilitators also ensures the sustainability of the program. The ATAP-NEPAH program has been implemented as part of the annual program of USM Medical Students Facilitator Team (MSFT). Every year, a new group of medical students are trained to become facilitators of ATAP-NEPAH.

This program was targeted to younger adolescents so that prevention of social problems could be made as early as possible because it has been reported that the mean age for adolescents to be engaged in social problems for the first time was between 14 to 15 years old (Health, 2017). Early exposure to health education may reduce the risk of starting the risky behavior such as sexual behavior (Erkut et al., 2013).

In this study, there was also improvement in the soft skills of adolescents who were selected as peer educators which was also reported in other studies (Brack, Millard, \& Shah, 2008). Through a few sessions of training of trainers, the students reported that their readiness in a few soft skill aspects were enhanced. The aspects include helping out in early detection and notification of peers' problems, trying 
to solve peers' problems according to their ability, recognizing peers' potential, motivating and supervising their peers and facilitating peer development activities.

Besides peer-to-peer approach, the positive impact of the program was contributed also by the use of interesting and interactive method of health education such as role play, drawing, debate, quizzes, and video show. Using interactive techniques and strategies, the students become more engaged in learning, retain more information, thus becoming more satisfied (Senthamarai, 2018). We acknowledge a few limitations in the assessment of the intervention effect. Change in behavior was not assessed because it requires longer time to follow up the participants.

\section{Conclusion}

ATAP-NEPAH program which is based on peer-to-peer health education improved the knowledge and attitude of adolescents towards healthy habits and risky behaviors as well as the adolescents' level of readiness to become peer educators

\section{Acknowledgement}

We would like to acknowledge Medical Students Facilitator Team (MSFT) of USM, Malaysian Association for Adolescent Health (MAAH), Kelantan National Population and Family Development Board (NPFDB), Reproductive Health Association of Kelantan (REHAK), Rhaudatus Sakinah Kelantan, lecturers, teachers and school students involved.

\section{References}

Abdi, F., \& Simbar, M. (2013). The peer education approach in adolescents-narrative review article. Iranian journal of public health, 42(11), 1200.

Ali, M. H. M., Osman, O. B., Ibrahim, M. A. M., \& Ahmed, W. A. M. (2015). The effect of AIDS peer health education on knowledge, attitudes, and practices of secondary school students in Khartoum, Sudan. AIMS public health, 2(4), 718.

Brack, A. B., Millard, M., \& Shah, K. (2008). Are peer educators really peers? Journal of American College Health, 56(5), 566-568.

Bretelle, F., Shojai, R., Brunet, J., Tardieu, S., Manca, M. C., Durant, J., . . Leonetti, G. (2014). Medical students as sexual health peer educators: who benefits more? BMC medical education, 14(1), 17.

Brown, B. B., Bakken, J. P., Ameringer, S. W., \& Mahon, S. D. (2008). A comprehensive conceptualization of the peer influence process in adolescence. Understanding peer influence in children and adolescents, 17-44.

Erkut, S., Grossman, J. M., Frye, A. A., Ceder, I., Charmaraman, L., \& Tracy, A. J. (2013). Can sex education delay early sexual debut? The Journal of Early Adolescence, 33(4), 482-497.

Health, I. f. P. (2017). National Health and Morbidity Survey (NHMS) 2017: Adolescent Health Survey 2017: Ministry of Health Kuala Lumpur, Malaysia.

Jobanputra, J., Clack, A. R., Cheeseman, G. J., Glasier, A., \& Riley, S. C. (1999). A feasibility study of adolescent sex education: medical students as peer educators in Edinburgh schools. BJOG: An International Journal of Obstetrics \& Gynaecology, 106(9), 887-891.

Layzer, C., Rosapep, L., \& Barr, S. (2017). Student Voices: Perspectives on Peer-to-Peer Sexual Health Education. Journal of School Health, 87(7), 513-523.

Maticka-Tyndale, E., \& Barnett, J. P. (2010). Peer-led interventions to reduce HIV risk of youth: a review. Evaluation and program planning, 33(2), 98-112.

Moran, M. B., Walker, M. W., Alexander, T. N., Jordan, J. W., \& Wagner, D. E. (2017). Why peer crowds matter: incorporating youth subcultures and values in health education campaigns. American journal of public health, 107(3), 389-395. 
DOI: https://doi.org/10.47405/mjssh.v6i3.719

Rahman, A. A., Rahman, R., Ibrahim, M. I., Salleh, H., Ismail, S. B., Ali, S. H., . . Ahmad, A. (2011). Knowledge of sexual and reproductive health among adolescents attending school in Kelantan, Malaysia. Southeast Asian Journal of Tropical Medicine \& Public Health, 42(3), 717-725.

Senthamarai, S. (2018). Interactive teaching strategies. Journal of Applied and Advanced Research, 3(1), S36-S38.

Toolkit, Y. P. E. (2005). Training of the Trainers. North Carolina: Family Health International.

Yeager, D. S., Dahl, R. E., \& Dweck, C. S. (2018). Why interventions to influence adolescent behavior often fail but could succeed. Perspectives on Psychological Science, 13(1), 101-122. 